\title{
Outcome Analysis of Chemoradiation in Unresectable Pancreatic Cancer Focusing on Treatment Sequencing Strategy
}

\author{
HYEON KANG KOH ${ }^{1}$, EUI KYU CHIE ${ }^{2,3}$, KYUBO KIM ${ }^{4}$, JIN-YOUNG JANG ${ }^{5}$, SUN WHE KIM ${ }^{5}$, \\ DO-YOUN OH ${ }^{6}$, SEOCK-AH IM ${ }^{6}$, YUNG-JUE BANG ${ }^{6}$ and SUNG W. HA ${ }^{2,3}$ \\ ${ }^{1}$ Department of Radiation Oncology, Konkuk Medical Center, Seoul, Republic of Korea; \\ Departments of ${ }^{2}$ Radiation Oncology, ${ }^{5}$ Surgery and ${ }^{6}$ Internal Medicine, \\ Seoul National University College of Medicine, Seoul, Republic of Korea; \\ ${ }^{3}$ Institute of Radiation Medicine, Medical Research Center, Seoul National University, Seoul, Republic of Korea; \\ ${ }^{4}$ Department of Radiation Oncology, Ewha Womans University School of Medicine, Seoul, Republic of Korea
}

\begin{abstract}
Aim: To analyze the outcomes of patients with unresectable pancreatic cancer after chemoradiotherapy (CCRT), focusing on sequencing strategy. Patients and Methods: Data of 144 patients treated from January 1989 to December 2013 were retrospectively analyzed. Patients were divided into the scheduled group $(N=27)$, salvage group $(N=37)$ and upfront group $(N=80)$ per CCRT and chemotherapy sequence. Results: With a median follow-up of 10.4 months (range=1.4-164.2), median overall survival (OS) was 13.5 months. Patients in the upfront group had inferior performance status and received a lower radiation dose ( $p=0.007$ and $p<0.001$, respectively). Higher radiation dose $(\geq 45 \mathrm{~Gy})$ was the sole prognosticator related with improved survival in multivariate $(p=0.001)$ analysis, whereas treatment sequence was not a significant prognostic factor ( $p=0.409)$. Conclusion: No difference was found among tested sequencing strategies that were all welltolerated, despite skewed distribution for performance and radiation dose. An upfront approach may be a viable option for patients with limited performance to undergo more active systemic chemotherapy.
\end{abstract}

It is well known that the prognosis of pancreatic cancer is dismal. Reported overall survival (OS) of patients with pancreatic cancer is only around $5 \%$ at 5 years $(1,2)$. Even

Correspondence to: Eui Kyu Chie, MD, Ph.D., Professor, Department of Radiation Oncology, Seoul National University College of Medicine, 101 Daehak-ro, Jongno-gu, Seoul, 03080, Republic of Korea. Tel: +82 220723705, Fax: +82 27653317, email: ekchie93@snu.ac.kr

Key Words: Pancreatic cancer, chemoradiotherapy, chemotherapy, radiation dose. though surgical resection remains the only curative treatment, only $20-25 \%$ of patients at the time of diagnosis are considered as candidates for surgery. Of remaining patients, about $30 \%$ are presented with locally advanced lesion without distant metastasis $(3,4)$.

Although chemotherapy plays pivotal role, concurrent chemoradiotherapy (CCRT) has also been employed based on reported survival benefit over radiotherapy (RT) alone or chemotherapy alone (5-9). Chemotherapies are often applied before CCRT both to control systemic disease upfront and to select proper candidates for CCRT (10). However, optimal sequencing strategies have not been elucidated. The aim of the study was to analyze the results of CCRT for patients with unresectable pancreatic cancer focusing on sequencing strategy.

\section{Patients and Methods}

After Institutional Review Board (IRB) approval, medical records of 178 consecutive patients with unresectable pancreatic cancer without distant metastasis, who underwent CCRT from January 1989 to December 2013, were reviewed. Twenty-seven patients were initially excluded as palliative surgery was offered prior to CCRT, while one patient was excluded due to incomplete medical record. Six patients were further excluded after intensive medical record and image review as lesions were deemed resectable by current standards. Unresectability was defined as lesions invading or encasing major arteries, such as superior mesenteric artery, celiac axis and hepatic artery and/or long segment invasion and encasement of major veins, such as superior mesenteric vein and portal vein, not amendable to reconstruction after review by panel of radiologists and surgeons. Therefore, a total of 144 patients were analyzed in the present study. Patients were retrospectively divided into three groups for comparison. Chemotherapy followed by scheduled CCRT, the scheduled group $(\mathrm{N}=27)$. Chemotherapy followed by initially unplanned CCRT, the salvage group $(\mathrm{N}=37)$. Lastly, CCRT offered as initial treatment, which may be followed by further chemotherapy, the upfront group $(\mathrm{N}=80)$. 
Table I. Patients' characteristics.

\begin{tabular}{|c|c|c|c|c|c|}
\hline \multirow[b]{2}{*}{ Characteristic } & \multicolumn{4}{|c|}{$\mathrm{N}(\%)$} & \multirow[b]{2}{*}{$p$-Value } \\
\hline & All & Scheduled & Salvage & Upfront & \\
\hline \multicolumn{6}{|l|}{ Age (years) } \\
\hline Median & 59.8 & 56.8 & 61.4 & 61.0 & $0.109 *$ \\
\hline Range & $32.6-78.4$ & $35.7-72.7$ & $46.0-77.3$ & $32.6-78.4$ & \\
\hline \multicolumn{6}{|l|}{ Gender } \\
\hline Female & $62(43.1)$ & $11(40.7)$ & $20(54.1)$ & $31(38.8)$ & $0.288^{\dagger}$ \\
\hline Male & $82(56.9)$ & $16(59.3)$ & $17(45.9)$ & $49(61.3)$ & \\
\hline \multicolumn{6}{|c|}{ Performance (ECOG) } \\
\hline $0-1$ & $122(84.7)$ & $26(96.3)$ & $35(94.6)$ & $61(76.3)$ & $0.007^{\dagger}$ \\
\hline $2-3$ & $22(15.3)$ & $1(3.7)$ & $2(5.4)$ & $19(23.8)$ & \\
\hline \multicolumn{6}{|l|}{ Tumor location } \\
\hline Head & $71(49.3)$ & $9(33.3)$ & $15(40.5)$ & $47(58.8)$ & $0.034^{\dagger}$ \\
\hline Body or tail & $73(50.7)$ & $18(66.7)$ & $22(59.5)$ & $33(41.3)$ & \\
\hline \multicolumn{6}{|c|}{ Lymph node involvement } \\
\hline No & $85(59.0)$ & $17(63.0)$ & 17 (45.9) & $51(63.8)$ & $0.171^{\dagger}$ \\
\hline Yes & $59(41.0)$ & $10(37.0)$ & $20(54.1)$ & $29(36.3)$ & \\
\hline \multicolumn{6}{|c|}{ Radiation dose (Gy) } \\
\hline Median & 50.4 & 55.8 & 54.0 & 40.0 & $<0.001 *$ \\
\hline Range & $40.0-59.4$ & $50.4-55.8$ & $40.0-59.4$ & $40.0-56.0$ & \\
\hline
\end{tabular}

ECOG, Eastern Cooperative Oncology Group. *One-way ANOVA test; ${ }^{\dagger}$ Chi-square test.

RT target volume contained primary tumor plus margin for microscopic disease extension and grossly enlarged lymph nodes, as well as elective regional nodal area. Dose over 45 Gy was confined to primary tumor and grossly enlarged lymph nodes.

All adverse events were evaluated using Common Terminology Criteria for Adverse Events version 4.0. Each event was scored regardless of the other and the highest grades of complications observed during CCRT were recorded. Late gastrointestinal toxicities related to RT were graded separately.

Comparisons of selected characteristics between patients among three groups were carried out using the Pearson's Chi-square test for categorical variables and the one-way ANOVA test for continuous variables. OS was counted from the first date of any kind of treatment to the date of death and calculated by the Kaplan-Meier method. Post-RT survival was defined as the duration between the last date of RT and the date of death. Log-rank test was performed for the comparison of OS depending on categorical variables. The backward Cox regression model was used for multivariate analysis and analysis of the effects of continuous variables on OS. Prognostic factors with $p<0.1$ in the univariate analysis were incorporated in multivariate analysis. Maxstat, a maximal Chi-square method in R2.13.0 (R Development Core Team, Vienna, Austria, http://www.Rproject.org) was used to define the optimal cut-off radiation dose to show maximal difference of OS. Statistical significance was defined as $p<0.05$ in a two-sided test. Data were analyzed using SPSS version 18.0 (SPSS, Inc., Chicago, IL, USA).

\section{Results}

Patients' characteristics. Median age at the start of the treatment was 59.8 years old (range=32.6-78.4). Patients' distribution was skewed for performance, lesion location and radiation dose. More patients in the upfront group had limited performance defined as Eastern Cooperative Oncology Group performance scale 2 or higher $(p=0.007)$. Head lesions were also more frequent in the upfront group $(p=0.034)$. Median radiation dose was statistically different among groups with $55.8 \mathrm{~Gy}$ (range=50.4-55.8), 54.0 Gy (range=40.0-59.4) and 40.0 Gy (range=40.0-56.0) for the scheduled group, the salvage group and the upfront group, respectively $(p<0.001)$. Other characteristics, including age, gender and frequency of lymph node involvement, were comparable among three groups (Table I).

Treatment. In the scheduled group, gemcitabine-based chemotherapy regimens were the mainstay of treatment. Combination with cisplatin was most frequently used with 2 cycles for one patient, 3 cycles for 18 patients and 4 cycles for the other patient. Other platinum combination regimens include two patients with 3 cycles with oxaliplatin and one patient with 2 cycles with carboplatin. Erlotinib combination was offered to two patients for 7 cycles and 4 cycles, respectively. Remaining two patients were treated with 2 cycles of gemcitabine and capecitabine. Response after scheduled chemotherapy was partial response for 4 patients and stable disease for 23 patients using Response Evaluation Criteria in Solid Tumors version 1.1 (RECIST). Employed chemotherapies during RT were capecitabine for 22 patients, two cycles of 5-fluorouracil (5-FU) for 2 patients and weekly gemcitabine for 3 patients. 
Gemcitabine-based chemotherapy was also most commonly used regimen in the salvage group. This included 2 cycles $(\mathrm{N}=4), 3$ cycles $(\mathrm{N}=4), 4$ cycles $(\mathrm{N}=1), 5$ cycles $(\mathrm{N}=1), 6$ cycles $(\mathrm{N}=3), 9$ cycles $(\mathrm{N}=3)$ and 12 cycles $(\mathrm{N}=1)$ of gemcitabine plus erlotinib $(\mathrm{N}=17), 2$ cycles $(\mathrm{N}=2), 3$ cycles $(\mathrm{N}=1), 4$ cycles $(\mathrm{N}=3)$ and 6 cycles $(\mathrm{N}=1)$ of gemcitabine plus cisplatin $(\mathrm{N}=7)$, one cycle $(\mathrm{N}=1), 2$ cycles $(\mathrm{N}=1), 3$ cycles $(\mathrm{N}=1)$ and 4 cycles $(\mathrm{N}=2)$ of gemcitabine alone $(\mathrm{N}=5), 3$ cycles $(\mathrm{N}=1)$ and 4 cycles $(\mathrm{N}=1)$ of gemcitabine, oxaliplatin and erlotinib $(\mathrm{N}=2), 15$ cycles of gemcitabine and capecitabine $(\mathrm{N}=1)$ and 7 cycles of gemcitabine and caboplatin $(\mathrm{N}=1)$. Three patients were initially treated with gemcitabine chemotherapy then had regimen changed to fluoropyrimidine-based chemotherapy; 5 cycles of gemcitabine followed by 2 cycles of capecitabine $(\mathrm{N}=1), 6$ cycles of gemcitabine then 2 cycles of 5 -FU $(\mathrm{N}=1)$ and 6 cycles of gemcitabine followed by 18 cycles of 5-FU $(\mathrm{N}=1)$. There was one patient undergoing 3 cycles of FOLFIRINOX (5-FU, leucovorin, irinotecan and oxaliplatin) prior to CCRT. Tumor responses by RECIST criteria were partial response in 4 patients, stable disease in 23 patients and progressive disease in 10 patients. During CCRT, 14 patients received weekly gemcitabine, 12 patients were treated with capecitabine, 7 patients were treated with 5-FU on Days 1-3 and Days 29-31, while three patients received 5-FU on Days 1-3. One patient received 2 cycles of gemcitabine.

In the upfront group, 56 patients received two cycles of 5FU, 8 patients underwent one cycle of $5-\mathrm{FU}, 13$ patients weekly gemcitabine and 3 patients daily capecitabine.

Median radiation dose were $55.8 \mathrm{~Gy}$ (range=50.4-55.8), 54.0 Gy (range=40.0-59.4) and 40.0 Gy (range=40.0-56.0) for the scheduled group, salvage group and upfront group, respectively.

Various regimens of chemotherapy following CCRT were offered to patients with suitable performance. Chemotherapy was given to 20 patients $(74.1 \%)$ in the scheduled group, 24 patients $(64.9 \%)$ in the salvage group and 31 patients $(38.8 \%)$ in the upfront group.

Overall survival. With the median follow-up duration of 10.4 months (range $=1.4-164.2$ ), the median OS was 13.5 months (95\% confidence interval $(\mathrm{CI})=11.49-15.51), 16.3$ months (95\% CI=14.43-18.17), 17.5 months (95\% CI=14.93-20.07) and 10.1 months (95\% $\mathrm{CI}=8.74-11.46)$ for all patients, scheduled group, salvage group and upfront group, respectively (Figure 1, $p=0.007$ ). Accordingly, post-RT median OS was 9.4 months $(95 \% \mathrm{CI}=8.17-10.63), 12.4$ months $(95 \% \mathrm{CI}=9.18$ 15.62), 10.8 months (95\% CI=7.25-14.35) and 8.8 months (95\% CI=7.82-10.63), respectively $(p=0.452)$.

Prognostic factors. Table II provides results of univariate and multivariate analyses of prognostic factors for OS. Maximal

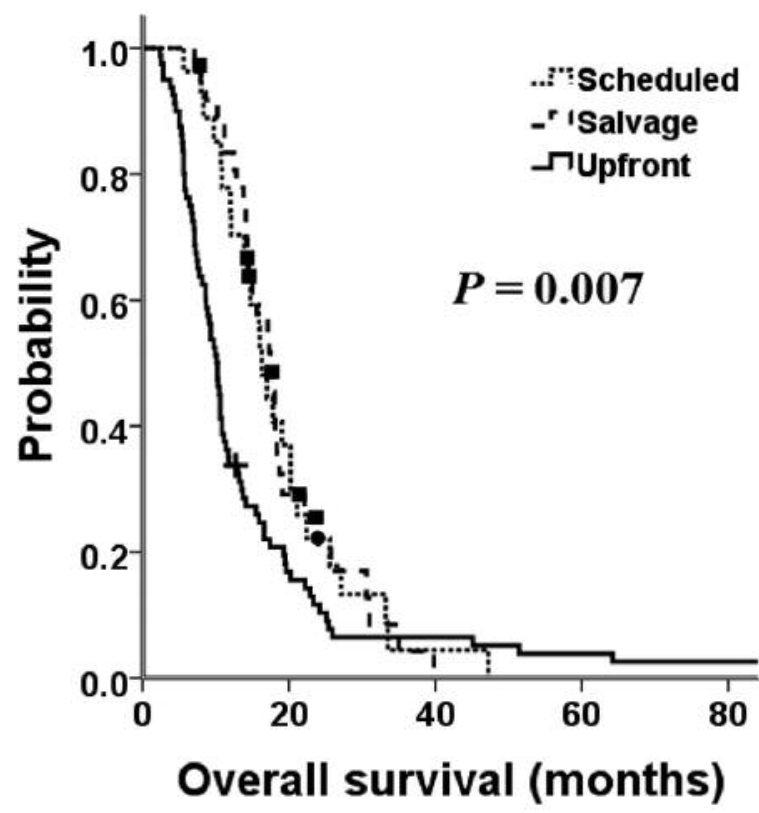

Figure 1. Kaplan-Meier survival curve per treatment sequence.

Chi-square test nominated $45 \mathrm{~Gy}$ as the optimal cut-off value for OS-related radiation dose (Figure 2, $p=0.038$ ). Radiation dose was the only significant factor with both univariate $(p=0.001)$ and multivariate $(p=0.001)$ analyses. In terms of post-RT OS, radiation dose was also a significant factor $(p=0.038)$. Treatment group was analyzed as a significant prognostic factor with univariate analysis for OS $(p=0.007)$, but lost its significance after multivariate analysis $(p=0.409)$. Other factors, such as age, gender, ECOG performance status, tumor location, lymph node involvement and carbohydrate antigen (CA) 19-9, were not deemed significant.

Adverse events. Details of recorded acute and late adverse events are as described in Table III. Most common grade 12 toxicity was nausea or vomiting in all three groups. There was no complication requiring surgical intervention.

\section{Discussion}

In this retrospective review of 144 patients treated with CCRT for unresectable pancreatic cancer, the median OS was 13.5 months. We showed that radiation dose was the only significant prognosticator in both univariate and multivariate analyses. Treatment sequence affected OS significantly with univariate analysis, but lost its significance after multivariate analysis, whereas post-RT OS was not significantly different across the groups. This could be due to selection bias or radiation dose effect on the scheduled and salvage group against the upfront group. 
Table II. Prognostic factor analysis.

\begin{tabular}{|c|c|c|c|c|c|c|c|}
\hline & \multirow[t]{2}{*}{$\mathrm{N}$} & \multirow{2}{*}{$\begin{array}{c}\text { OS } \\
\text { (median, months) }\end{array}$} & \multicolumn{2}{|c|}{$p$-Value } & \multirow{2}{*}{$\begin{array}{c}\text { Post-RT OS } \\
\text { (median, months) }\end{array}$} & \multicolumn{2}{|c|}{$p$-Value } \\
\hline & & & UVA* & $\mathrm{MVA}^{\dagger}$ & & UVA* & $\mathrm{MVA}^{\dagger}$ \\
\hline \multicolumn{8}{|l|}{ Age } \\
\hline$<70$ years & 119 & 13.8 & 0.903 & - & 9.4 & 0.868 & - \\
\hline$\geq 70$ years & 25 & 13.2 & & & 9.6 & & \\
\hline \multicolumn{8}{|l|}{ Gender } \\
\hline Female & 62 & 14.1 & 0.832 & - & 10.2 & 0.884 & - \\
\hline Male & 82 & 11.2 & & & 9.3 & & \\
\hline \multicolumn{8}{|c|}{ Performance (ECOG) } \\
\hline $0-1$ & 122 & 14.2 & 0.208 & - & 10.0 & 0.419 & - \\
\hline $2-3$ & 22 & 9.3 & & & 5.6 & & \\
\hline \multicolumn{8}{|l|}{ Tumor location } \\
\hline Head & 71 & 11.2 & 0.794 & - & 8.5 & 0.770 & - \\
\hline Body or tail & 73 & 13.8 & & & 10.4 & & \\
\hline \multicolumn{8}{|c|}{ Lymph node involvement } \\
\hline No & 85 & 12.8 & 0.626 & - & 9.4 & 0.914 & - \\
\hline Yes & 59 & 14.1 & & & 9.7 & & \\
\hline \multicolumn{8}{|c|}{ Initial CA 19-9 level ${ }^{\ddagger}$} \\
\hline$<1000 \mathrm{U} / \mathrm{ml}$ & 71 & 15.6 & 0.581 & - & 10.8 & 0.591 & - \\
\hline$\geq 1000 \mathrm{U} / \mathrm{ml}$ & 33 & 14.2 & & & 9.9 & & \\
\hline \multicolumn{8}{|c|}{ Post-RT CA 19-9 level } \\
\hline$<37 \mathrm{U} / \mathrm{ml}$ & 33 & 17.8 & 0.126 & - & 12.4 & 0.409 & - \\
\hline$\geq 37 \mathrm{U} / \mathrm{ml}$ & 64 & 14.3 & & & 10.8 & & \\
\hline \multicolumn{8}{|l|}{ Radiation dose } \\
\hline$\leq 45 \mathrm{~Gy}$ & 57 & 9.3 & 0.001 & 0.001 & 7.7 & 0.038 & 0.039 \\
\hline$>45$ Gy & 87 & 16.0 & & & 12.2 & & \\
\hline \multicolumn{8}{|l|}{ Treatment group } \\
\hline Scheduled & 27 & 16.3 & 0.007 & 0.409 & 12.4 & 0.452 & - \\
\hline Salvage & 37 & 17.5 & & & 10.8 & & \\
\hline Upfront & 80 & 10.1 & & & 8.8 & & \\
\hline
\end{tabular}

OS, Overall survival; mo, months; UVA, univariate analysis; MVA, multivariate analysis; ECOG, Eastern Cooperative Oncology Group; CA 19-9, carbohydrate antigen 19-9. * Log-rank test; ${ }^{\dagger}$ Cox regression analysis. $\stackrel{\ddagger}{\dagger}$ atients with missing value excluded from the analysis.

There is an on-going debate on optimal treatment for unresectable pancreatic cancer. Various combinations of RT, chemotherapy and CCRT have been employed in practice and studied. However, best treatment sequence, duration, dose and regimen have yet to be established as reflected in studies reported over period of time from GITSG, FFCD/SFRO, GERCOR and LAP (5, 6, 8, 11-13).

Many researchers have contributed in search of the optimal chemotherapy regimen for unresectable pancreatic cancer, as well. Most recent studies have shown improved results with more active FOLFIRINOX regimen over gemcitabine and more traditionally used fluoropyrimidinebased chemotherapy $(14,15)$. However, this was accompanied by significant toxicities. Combining gemcitabine with nanoparticle albumin-bound (nab)paclitaxel was shown to have similar efficacy with less toxicity (16). In the current study, the majority of employed chemotherapy regimens was gemcitabine-based, except for one patient undergoing FOLFIRINOX regimen and none treated with combination nab-paclitaxel. This is, at least in part, owing to period of patient accrual for analysis, when results of aforementioned studies were unavailable.

For CCRT, Li et al. (17) reported improved OS in gemcitabine-treated group compared to 5-FU-treated group $(p=0.027)$. In randomized phase II trial, Mukherjee et al. (18) suggested capecitabine-based CCRT might be better than gemcitabine-based CCRT after induction chemotherapy $(p=0.012)$. In the current study, patients were treated with 5FU, gemcitabine and capecitabine reflecting transition of the mainstay of combined chemotherapy with RT over accrued time period.

Treatment sequencing strategy employing both chemotherapy and CCRT has long been an issue, when CCRT was incorporated as a component of a treatment. With advance in chemotherapy, treatment sequence has been shifted from upfront CCRT followed by chemotherapy, as in early GITSG studies to chemotherapy followed by CCRT, as in a more recent LAP07 study. The latter approach has been favored 


\begin{tabular}{|c|c|c|c|c|c|c|}
\hline & \multicolumn{6}{|c|}{ Number of patients $(\% *)$} \\
\hline & \multicolumn{3}{|c|}{ Grade 1-2 } & \multicolumn{3}{|c|}{ Grade 3-4 } \\
\hline & Scheduled & Salvage & Upfront & Scheduled & Salvage & Upfront \\
\hline \multicolumn{7}{|l|}{ Hematological toxicity } \\
\hline Leukopenia & $4(14.8)$ & $12(32.4)$ & $20(25.0)$ & $1(3.7)$ & $4(10.8)$ & $3(3.8)$ \\
\hline Neutropenia & $2(7.4)$ & 7 (18.9) & $5(6.3)$ & $0(0.0)$ & $1(2.7)$ & $3(3.8)$ \\
\hline Anemia & $5(18.5)$ & $5(13.5)$ & $8(10.0)$ & $0(0.0)$ & $2(5.4)$ & $0(0.0)$ \\
\hline Thrombocytopenia & $5(18.5)$ & $1(2.7)$ & $5(6.3)$ & $0(0.0)$ & $1(2.7)$ & $1(1.3)$ \\
\hline Nausea/Vomiting & $13(48.1)$ & $6(16.2)$ & $37(46.3)$ & $0(0.0)$ & $0(0.0)$ & $0(0.0)$ \\
\hline Anorexia & $0(0.0)$ & $1(2.7)$ & $2(2.5)$ & $1(3.7)$ & $0(0.0)$ & $0(0.0)$ \\
\hline Diarrhea & $3(11.1)$ & $1(2.7)$ & $5(6.3)$ & $0(0.0)$ & $0(0.0)$ & $0(0.0)$ \\
\hline Enteritis & $5(18.5)$ & $3(8.1)$ & $2(2.5)$ & $0(0.0)$ & $0(0.0)$ & $0(0.0)$ \\
\hline Skin rash & $1(3.7)$ & $0(0.0)$ & $0(0.0)$ & $0(0.0)$ & $0(0.0)$ & $0(0.0)$ \\
\hline Infection & $0(0.0)$ & $0(0.0)$ & $0(0.0)$ & $0(0.0)$ & $0(0.0)$ & $1(1.3)$ \\
\hline Dizziness & $0(0.0)$ & $0(0.0)$ & $2(2.5)$ & $0(0.0)$ & $0(0.0)$ & $0(0.0)$ \\
\hline Hand foot syndrome & $0(0.0)$ & $0(0.0)$ & $0(0.0)$ & $1(3.7)$ & $0(0.0)$ & $0(0.0)$ \\
\hline Late GI toxicity & $0(0.0)$ & $0(0.0)$ & $0(0.0)$ & $1(3.7)$ & $0(0.0)$ & $1(1.3)$ \\
\hline
\end{tabular}

CTCAE, Common Terminology Criteria for Adverse Events; GI, gastrointestinal. *Percentage of each subgroup (scheduled group=27 patients, salvage group $=37$ patients and upfront group $=80$ patients, respectively).

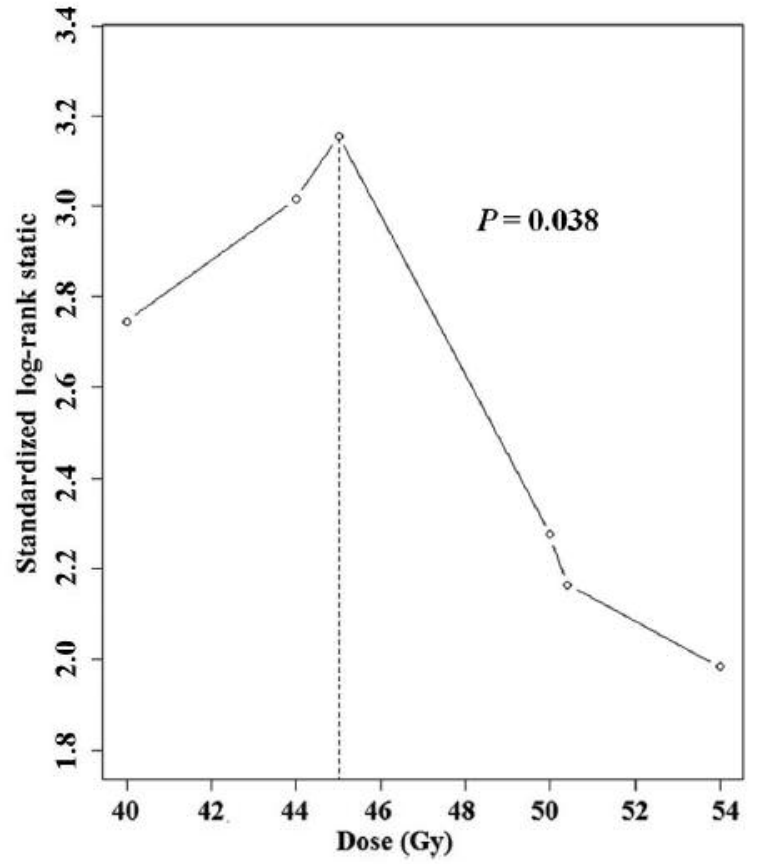

Figure 2. Maximal Chi-square method: the cut-off value of radiation dose was set to what provided the best separation of OS into two groups, where the standardized log-rank statistics take their maximum.

recently based on two major factors; First, full dose delivery of active chemotherapy for fit patients and, second, possible selection for patients more suitable to benefit from additional locoregional modality. Some of the best treatment results are reported from more recent phase II studies employing induction chemotherapy followed by CCRT $(19,20)$. Patients accrued in the current study followed this trend with more patients treated with upfront approach followed by salvage approach and then, more recently, with scheduled sequencing.

As shown in results, survival was significantly different for treated group on univariate analysis. However, treatment group lost its statistical significance after correcting for skewed distribution of radiation dose, that was the sole significant prognosticator, through multivariate analysis. Of note is that, unlike in prospective trials, patient selection is inherently biased. In this case, patients without distant metastasis after initial chemotherapy, either as scheduled or salvage, were selected to undergo CCRT. On the contrary, in the upfront group, as it was the initial treatment offered, all patients were included. Thus, patient selection would have been biased against upfront group. Furthermore, there was no difference in post-RT survival irrespective of treatment group. This might have stemmed from the limited number of patients, as there was clearly numerical difference across the treatment strategy. Thus, these results may provide a rationale in favor of either scheduled or salvage approach. However, considering selection bias against upfront CCRT and skewed distribution of patients with poor performance, this could also be interpreted as a safe and effective application of CCRT not only for those not deemed suitable for systemic chemotherapy, especially more active and potent treatment with increased toxicity, but also for general 
application as well. Incorporating CCRT as a component of treatment resulted in improved survival in comparison to chemotherapy alone within the same institution (21). Thus, CCRT, as a component of treatment for patients with unresectable/non-metastatic pancreatic cancer, needs to be further tested. Optimal timing of CCRT, in addition to other aspects of treatment, including optimal regimen, may be a subject for further studies.

It has also been a separate question to define an optimal radiation dose in regards to both efficacy and safety for CCRT in unresectable pancreatic cancer. Dose escalation has been attempted cautiously due to increased risk of detrimental toxicities. Best example maybe previously mentioned FFCD/SFRO study, where patients treated to high-dose radiation with active chemotherapy regimen resulted in inferior survival (12). Similarly, in a retrospective study based on national cancer data base, Hall et al. examined radiation dose escalation above $40 \mathrm{~Gy}$ in CCRT but failed to validate the benefit in terms of OS (22). However, more than 54 Gy of radiation dose was associated with better OS in a more recent retrospective study by Golden et al. (23). Factor to be considered here is relevant expertise in the patient care. It is well known that expertise in surgical resection, reflected as hospital load or surgical volume, plays significant role, more so in pancreatic cancer than any other malignancies (24). For radiotherapy, this may be termed as importance of quality assurance, which has been highlighted through a multicenter prospective randomized study conducted by Radiation Therapy Oncology Group (RTOG), where adherence to the protocol resulted in not only significantly improved survival but also significantly decreased toxicity (25). In the present study, higher radiation dose ( $\geq 45 \mathrm{~Gy}$ ) showed improved OS in both univariate and multivariate analyses, sustaining significance as a continuous variable as well. Further analysis awaits to confirm radiation dose effect on OS in patients with unresectable pancreatic cancer treated with modern advanced radiation technique adhering to target volume and normal tissue delineation guidelines.

Our study has several limitations. First, given its retrospective nature, the potential for selection bias cannot be excluded as discussed previously. Second, patients were accrued in a time period of over 25 years. This wide range of accrual is somewhat reflected in various chemotherapy regimens employed. Also, CA 19-9 values, known to be important prognostic factor $(23,26)$, were unavailable for more than one-third of the patients, especially those treated in earlier period, which may have impacted current prognosticator analysis.

In conclusion, CCRT could be a reasonable treatment option for unresectable pancreatic cancer, especially in patients not fit for more active chemotherapy. Results from the current study also add additional evidence in favor of radiation dose escalation. Optimal sequence for chemotherapy and CCRT combination should be given a chance to be evaluated through a prospective randomized controlled trial.

\section{Conflicts of Interest}

None.

\section{References}

1 Siegel R, Ma J, Zou Z and Jemal A: Cancer statistics, 2014. CA Cancer J Clin 64: 9-29, 2014.

2 Jung KW, Won YJ, Kong HJ, Oh CM, Cho H, Lee DH and Lee $\mathrm{KH}$ : Cancer statistics in Korea: Incidence, mortality, survival, and prevalence in 2012. Cancer Res Treat 47: 127-141, 2015

3 Werner J, Combs SE, Springfeld C, Hartwig W, Hackert T and Büchler MW: Advanced-stage pancreatic cancer: Therapy options. Nat Rev Clin Oncol 10: 323-33, 2013.

4 Cardenes HR, Chiorean EG, Dewitt J, Schmidt M and Loehrer P: Locally advanced pancreatic cancer: current therapeutic approach. Oncologist 11: 612-623, 2006.

5 Moertel CG, Childs DS Jr., Reitemeier RJ, Colby MY Jr and Holbrook MA: Combined 5-fluorouracil and supervoltage radiation therapy of locally unresectable gastrointestinal cancer. Lancet 2: 865-867, 1969.

6 Moertel CG, Frytak S, Hahn RG, O'Connell MJ, Reitemeier RJ, Rubin J, Schutt AJ, Weiland LH, Childs DS, Holbrook MA, Lavin PT, Livstone E, Spiro H, Knowlton A, Kalser M, Barkin J, Lessner H, Mann-Kaplan R, Ramming K, Douglas HO Jr, Thomas P, Nave H, Bateman J, Lokich J, Brooks J, Chaffey J, Corson JM, Zamcheck N and Novak JW: Therapy of locally unresectable pancreatic carcinoma: A randomized comparison of high dose (6000 rads) radiation alone, moderate dose radiation (4000 rads + 5-fluorouracil), and high dose radiation + 5fluorouracil: The Gastrointestinal Tumor Study Group. Cancer 48: 1705-1710, 1981.

7 Sultana A, Tudur Smith C, Cunningham D, Starling N, Tait D, Neoptolemos JP and Ghaneh P: Systematic review, including meta-analyses, on the management of locally advanced pancreatic cancer using radiation/combined modality therapy. $\mathrm{Br}$ J Cancer 96: 1183-1190, 2007.

8 Gastrointestinal Tumor Study Group: Treatment of locally unresectable carcinoma of the pancreas: Comparison of combined-modality therapy (chemotherapy plus radiotherapy) to chemotherapy alone. J Natl Cancer Inst 80: 751-755, 1988.

9 Loehrer PJ Sr, Feng Y, Cardenes H, Wagner L, Brell JM, Cella D, Flynn P, Ramanathan RK, Crane CH, Alberts SR and Benson $\mathrm{AB}$ 3rd: Gemcitabine alone versus gemcitabine plus radiotherapy in patients with locally advanced pancreatic cancer: An Eastern Cooperative Oncology Group trial. J Clin Oncol 29: 4105-4112, 2011.

10 Esnaola NF, Chaudhary UB, O'Brien P, Garrett-Mayer E, Camp ER, Thomas MB, Cole DJ, Montero AJ, Hoffman BJ, Romagnuolo J, Orwat KP and Marshall DT: Phase 2 trial of induction gemcitabine, oxaliplatin, and cetuximab followed by selective capecitabine-based chemoradiation in patients with borderline resectable or unresectable locally advanced pancreatic cancer. Int J Radiat Oncol Biol Phys 88: 837-844, 2014. 
11 Huguet F, André T, Hammel P, Artru P, Balosso J, Selle F, Deniaud-Alexandre E, Ruszniewski P, Touboul E, Labianca R, de Gramont A and Louvet C: Impact of chemoradiotherapy after disease control with chemotherapy in locally advanced pancreatic adenocarcinoma in GERCOR phase II and III studies. J Clin Oncol 25: 326-331, 2007.

12 Chauffert B, Mornex F, Bonnetain F, Rougier P, Mariette C, Bouché O, Bosset JF, Aparicio T, Mineur L, Azzedine A, Hammel P, Butel J, Stremsdoerfer N, Maingon P and Bedenne L: Phase III trial comparing intensive induction chemoradiotherapy (60 Gy, infusional 5-FU and intermittent cisplatin) followed by maintenance gemcitabine with gemcitabine alone for locally advanced unresectable pancreatic cancer. Definitive results of the 2000-01 FFCD/SFRO study. Ann Oncol 19: 1592-1599, 2008.

13 Hammel P, Huguet F, Laethem JV, Goldstein D, Glimelius B, Artru P, Borbath I, Bouche O, Shannon J, Andre T, Mineur L, Chibaudel B, Bonnetain F and Louvet C: Comparison of chemoradiotherapy (CRT) and chemotherapy (CT) in patients with a locally advanced pancreatic cancer (LAPC) controlled after 4 months of gemcitabine with or without erlotinib: Final results of the international phase III LAP 07 study. J Clin Oncol 2013 (suppl; abstr LBA4003).

14 Conroy T, Desseigne F, Ychou M, Bouche O, GuimbaudR, Becouarn Y, Adenis A, Raoul JL, Gourgou Bourgade S, de la Fouchardiere C, Bennouna J, Bachet JB, Khemissa-Akouz F, Pere-Verge D, Delbaldo C, Assenat E, Chauffert B, Michel P, Montoto-Grillot $\mathrm{C}$ and Ducreux M: Groupe Tumeurs Digestives of Unicancer: PRODIGE Intergroup: FOLFIRINOX versus gemcitabinefor metastatic pancreatic cancer. N Engl J Med 364: 1817-1825, 2011.

15 Petrelli F, Coinu A, Borgonovo K, Cabiddu M, Ghilardi M, Lonati V, Aitini E and Barni S; Gruppo Italiano per lo Studio dei Carcinomidell' Apparato Digerente (GISCAD). FOLFIRINOXbased neoadjuvant therapy in borderline resectable or unresectable pancreatic cancer: A meta-analytical review of published studies. Pancreas 44: 515-521, 2015.

16 Goldstein D, El-Maraghi RH, Hammel P, Heinemann V, Kunzmann V, Sastre J, Scheithauer W, Siena S, Tabernero J, Teixeira L, Tortora G, Van Laethem JL, Young R, Penenberg DN, Lu B, Romano A and Von Hoff DD: nab-Paclitaxel plus gemcitabine for metastatic pancreatic cancer: Long-term survival from a phase III trial. J Natl Cancer Inst 107(2), 2015.

17 Li CP, Chao Y, Chi KH, Chan WK, Teng HC, Lee RC, Chang FY, Lee SD and Yen SH: Concurrent chemoradiotherapy treatment of locally advanced pancreatic cancer: Gemcitabine versus 5-fluorouracil, a randomized controlled study. Int J Radiat Oncol Biol Phys 57: 98-104, 2003.

18 Mukherjee S, Hurt CN, Bridgewater J, Falk S, Cummins S, Wasan H, Crosby T, Jephcott C, Roy R, Radhakrishna G, McDonald A, Ray R, Joseph G, Staffurth J, Abrams RA, Griffiths $\mathrm{G}$ and Maughan T: Gemcitabine-based or capecitabinebased chemoradiotherapy for locally advanced pancreatic cancer (SCALOP): A multicentre, randomized, phase 2 trial. Lancet Oncol 14: 317-326, 2013.
19 Crane CH, Varadhachary GR, Yordy JS, Staerkel GA, Javle MM, Safran H, Haque W, Hobbs BD, Krishnan S, Fleming JB, Das P, Lee JE, Abbruzzese JL, Wolff RA: Phase II trial of cetuximab, gemcitabine, and oxaliplatin followed by chemoradiation with cetuximab for locally advanced (T4) pancreatic adenocarcinoma: Correlation of Smad4 (Dpc4) immunostaining with pattern of disease progression. J Clin Oncol 29: 3037-3043, 2011.

20 Kim JS, Lim JH, Kim JH, Im SA, Chie EK, Hwang JH, Kim TY, Bang YJ, Ha SW and Yoon YB: Phase II clinical trial of induction chemotherapy with fixed dose rate gemcitabine and cisplatin followed by concurrent chemoradiotherapy with capecitabine for locally advanced pancreatic cancer. Cancer Chemother Pharmacol 70: 381-389, 2012.

21 Choi Y, Oh DY, Kim K, Chie EK, Kim TY, Lee KH, Han SW, Im SA, Kim TY, Ha SW and Bang YJ: Concurrent chemoradiotherapy versus chemotherapy alone for unresectable locally advanced pancreatic cancer: A retrospective cohort study. Cancer Res Treat 48: 1045-55, 2016.

22 Hall WA, Colbert LE, Nickleach D, Switchenko J, Liu Y, Gillespie T, Lipscomb J, Hardy C, Kooby DA, Prabhu RS, Kauh $\mathrm{J}$ and Landry JC: The influence of radiation therapy dose escalation on overall survival in unresectable pancreatic adenocarcinoma. J Gastrointest Oncol 5: 77-85, 2014.

23 Golden DW, Novak CJ, Minsky BD and Liauw SL: Radiation dose $\geq 54$ Gy and CA 19-9 response are associated with improved survival for unresectable, non-metastatic pancreatic cancer treated with chemoradiation. Radiat Oncol 7: 156, 2012.

24 Birkmeyer JD, Siewers AE, Finlayson EV, Stukel TA, Lucas FL, Batista I, Welch HG and Wennberg DE: Hospital volume and surgical mortality in the United States. N Engl J Med 346: 11281137, 2002.

25 Abrams RA, Winter KA, Regine WF, Safran H, Hoffman JP, Lustig R, Konski AA, Benson AB, Macdonald JS, Rich TA and Willett CG: Failure to adhere to protocol specified radiation therapy guidelines was associated with decreased survival in RTOG 9704 - a phase III trial of adjuvant chemotherapy and chemoradiotherapy for patients with resected adenocarcinoma of the pancreas. Int J Radiat Oncol Biol Phys 82: 809-816, 2012.

26 Yang GY, Malik NK, Chandrasekhar R, Ma WW, Flaherty L, Iyer R, Kuvshinoff B, Gibbs J, Wilding G, Warren G and May KS: Change in CA 19-9 levels after chemoradiotherapy predicts survival in patients with locally advanced unresectable pancreatic cancer. J Gastrointest Oncol 4: 361-369, 2013.
Received August 10, 2016

Revised September 8, 2016

Accepted September 9, 2016 